\title{
Study on Carbody Flexible Vibration Considering Layout of underneath Equipment and Doors
}

\author{
Hangxing Ye, Jing Zeng*, Qunsheng Wang and Xiuhui Han ${ }^{*}$ \\ *State Key Laboratory of Traction Power, Southwest Jiaotong University \\ No. 111, First Section, North of Second Ring Road, Chengdu, Sichuan, 610031, P. R. CHINA \\ Email:yehangxing123@163.com
}

\begin{abstract}
Keywords: EMU, flexible vibration, underneath equipment
Abstract. Due to the layout of the door in the middle of the carbody and air-conditioning installation hole at the top, the flexural rigidity of carbody structure decreased obviously based on the modal frequencies calculated by finite element model (FEM) .Dynamic vibration absorber (DVA) was applied to restrain the vibration of the carbody. A 3D rigid-flexible coupled vehicle dynamics model was established by combining the multibody dynamics theory with the FEM and underneath equipment to measured track excitation. The traction converter with high weight is selected to be the only underneath equipment. The result shows that the elastic connection between carbody and traction converter has a significant influence on carbody vibration. Compared with the rigid connection, the elastic connection can reduce the vibration of carbody to a large extent. The reduction of vertical vibration is more obvious than the lateral vibration. The underneath equipment of carbody can be regarded as a dynamic vibration absorber(DVA) to reduce the flexible vibration of carbody. Besides,, the suspension parameters of elastic connection greatly affect the vibration of carbody and traction converter.
\end{abstract}

\section{Introduction}

With the increasing development of high-speed rail technology, the development of China EMUs(Electric Multiple Unit) rapid different speed grades grows quickly. Among them, the speed of $250 \mathrm{~km} / \mathrm{h}$ EMU used inter-city commuter to shorten distance of business travel between the city and the region. Unlike the high-speed railway and subway, inter-city EMU has its unique style, with a large transport capacity, start-stop fast, easy-parking station, quickness and efficiency, etc.

One of the basic design criteria of a high-speed rail development is lightweight body design. It can effectively reduce the interaction between the wheel and rail contacts, and reduce production costs. However, this will reduce stability of the vehicle body, thus reducing passengers' ride comfort ${ }^{[1-4]}$. Therefore, considering the flexible vibration of the vehicle body in the vehicle research process has drawn increasing attention.

Currently, most EMUs are equipped with multiple unit models. Many devices are installed on the vehicle chassis, such as traction transformer, traction converter, brake units, etc. Auxiliary equipments, weighing from tens of kilograms to several tons, hang at the bottom of the vehicle body. This design has a significant influence on the body's vertical bending frequency. A very effective method is tto introduce the suspension system, taking into account the suspension device as DVA, and select appropriate suspension parameters to reduce the flexible vibration of the vehicle body ${ }^{[5-7]}$.

Diana modeled the carbody as a flexible beam to analysis the impact of flexible vibration of carbody on riding comforts of high-speed passenger car using multi-body dynamics (MBS) theory. In addition, the establishment of rigidness-flexiblility coupled model is designed to simulate the response of the vehicle and equipment tracking incentives. Yang and Lee modeled body of Timoshenko beam with limited time to discuss the dynamic response of the vehicle worse track irregularity.

A side view of one type of inter-city EMU vehicle is shown in Figure 1. Compared with the high-speed EMU, this car optimizes doors in the middle of caibody and top of the air-conditioning installation hole. This structure will inevitably have a significant impact upon flexible vibration of the vehicle body. Consequently, if the vehicle body can be equated with rectangular beam structure, the 
vertical loading direction of the thin-walled rectangular moment of inertia can be described as follows:

$$
I=I_{1}+I_{2}=\frac{H^{3}(B-b)}{12}+\frac{b\left(\mathrm{H}^{3}-\mathrm{h}^{3}\right)}{12}=\frac{B H^{3}-b h^{3}}{12}
$$

$\mathrm{B}$ and $\mathrm{H}$ are the outer sizes, whereas $\mathrm{b}$ and $\mathrm{h}$ refer to inner sizes.

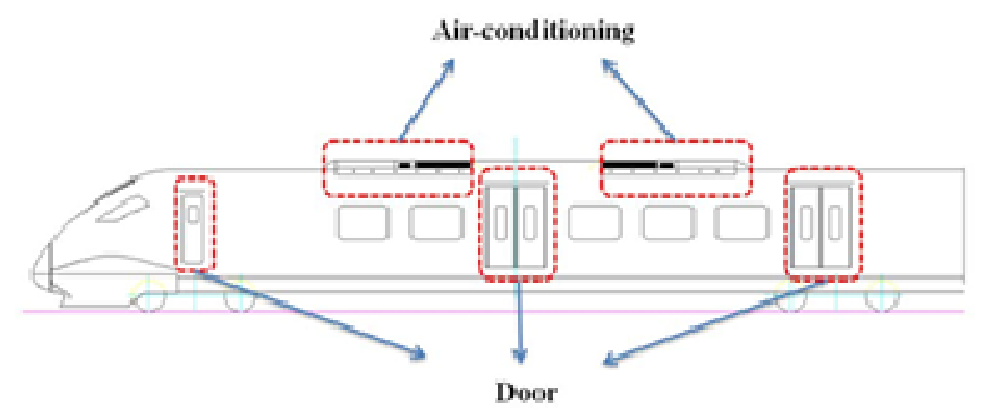

Fig.1 The side view of some inter-city EMU

According to eq. (1), the flexural stiffness of rectangular beam can be expressed as:

$$
E I=\frac{E\left(B H^{3}-b h^{3}\right)}{12}
$$

This paper analyzes the finite element model of the vehicle based on vibration mode. Afterwards, it adjusts the 3D flexible coupling dynamics model car group to consider the establishment of a body under flexible vibration equipment. It turns out the body flexible vibration influences exploration.Furthermore, it analyzes the different suspension parameters that impact rigidity and flexibility of the connection between the body and suspension equipment. Finally, a reasonable layout design for the carbody underneath equipment is suggested ${ }^{[8]}$.

\section{Establishment of dynamic model}

\section{Motion equation of carbody and underneath equipment}

As shown in Figure 2, the vehicle body is modeled as an Euler -Bernoulli beam and the equipment mounted on the chassis of the device is regarded as DVA. The impact of underneath equipment on the natural frequency of vehicle body vibration can be studied using the Euler Bernoulli beam body and the device coupled with vibration model.

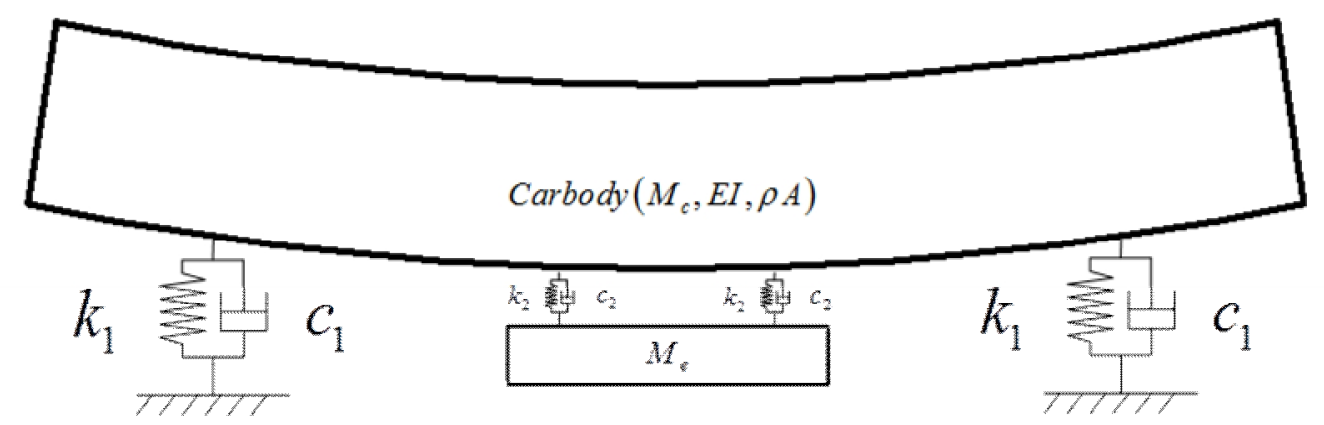

Fig. 2 The Euler-Bernoulli beam body and equipment coupled vibration model.

The front and rear bogies were replaced by spring-damper elements $\left(k_{1}, c_{1}\right)$ in parallel. The above partial differential equation model of the vehicle body can be expressed as: 


$$
E I \frac{\partial^{4} z(x, t)}{\partial x^{4}}+\mu I \frac{\partial^{5} z(x, t)}{\partial t \partial x^{4}}+\rho A \frac{\partial^{2} z(x, t)}{\partial t^{2}}=\sum_{i=1}^{2} f_{s i} \delta\left(x-x_{s i}\right)+\sum_{i=1}^{2} f_{e i} \delta\left(x-x_{e i}\right)
$$

where the first term on the right side is theflexible suspension force of front and rear bogie, while the second term represents the flexible suspension force of underneath equipment. The underneath equipment has two degrees of freedom: drifting and nod, and it is connected to the body by rubber $\operatorname{spring}\left(k_{2}, c_{2}\right)$. Considering the first $\mathrm{N}$ model of carbody, the vibration displacement equipment is:

$$
z(x, t)=z_{c}(t)+\left(x-\frac{L}{2}\right) \theta_{c}(t)+\sum_{i=3}^{N} Y_{i}(x) q_{i}(t)
$$

where the first and second term on the right side represent the drifting movement and nodding motion, whereas the third term fuctions as the flexible vibration of carbody. Substitution of equation (4) into (3) gives the integral expression of carbody movement equation:

$$
\left\{\begin{array}{l}
(t)+2 \xi_{i} \omega_{i} \bigotimes_{\imath}(t)+\omega_{i}^{2} q_{i}(t) \\
=\sum_{i=3}^{n}\left(\sum_{j=1}^{2} \frac{Y_{i}\left(x_{s j}\right)}{M_{c}} f_{s j}+\sum_{j=1}^{2} \frac{Y_{i}\left(x_{e j}\right)}{M_{c}} f_{e j}\right) \\
M_{c}(t)=\sum_{i=1}^{2} f_{s i}+\sum_{i=1}^{2} f_{e i} \\
I_{c} \oiint_{c}^{2}(t)=\sum_{i=1}^{2} f_{s i}\left(x_{s i}-\frac{L}{2}\right)+\sum_{i=1}^{2} f_{e i}\left(x_{e i}-\frac{L}{2}\right)
\end{array}\right.
$$

Moreover, the equation of underneath equipment movement can be expressed as:

$$
\left\{\begin{array}{l}
M_{e} \sum_{e}=\sum_{i=1}^{2} f_{e i} \\
I_{e} \theta_{e}^{\alpha_{e}}=\sum_{i=1}^{2} f_{e i}\left(x_{e i}-\frac{x_{e 1}+x_{e 2}}{2}\right)
\end{array}\right.
$$

Based on the eq.(3)-(6), the amplitude frequency characteristic curve of the car body can be calculated simultaneously, taking consideration of the position of the air spring and the sinusoidal excitation. Then, the ratio of the steady-state response amplitude and the excitation amplitude, which is called the dynamic amplification factor, can be subsequently obtained.

The above section analyzes the content of the main body based on the equivalent Euler-Bernoulli beam model, but the model does not actually reflect the actual complex flexible vibration body structure. Therefore, based on the principle mode superposition method, a 3D rigid-flexible coupled with vehicle system dynamics simulation model was built on the basis of multi-body system theory (MBS) and finite element method (FEM) by SIMPACK and ANSYS to analyze the matching parameters between the underneath equipment and the carbody.

\section{Dynamic rigidness-flexiblility coupled model of vehicle system}

According to the modal superposition method, the standard input file needs to be generated in ANSYS and SIMPACK. The body of the main modes and frequencies are shown in Figure 3. It had a significant impact on the layout of the top of the door and the vibration frequency of the central body of the air conditioning installation holes. It will reduce frequency of vibration of the vehicle body. 


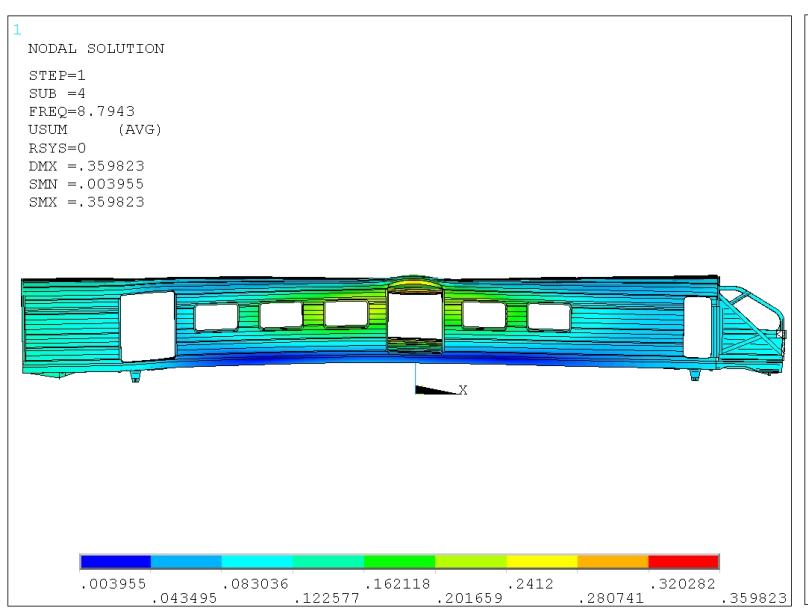

(a) $8.79 \mathrm{~Hz}$

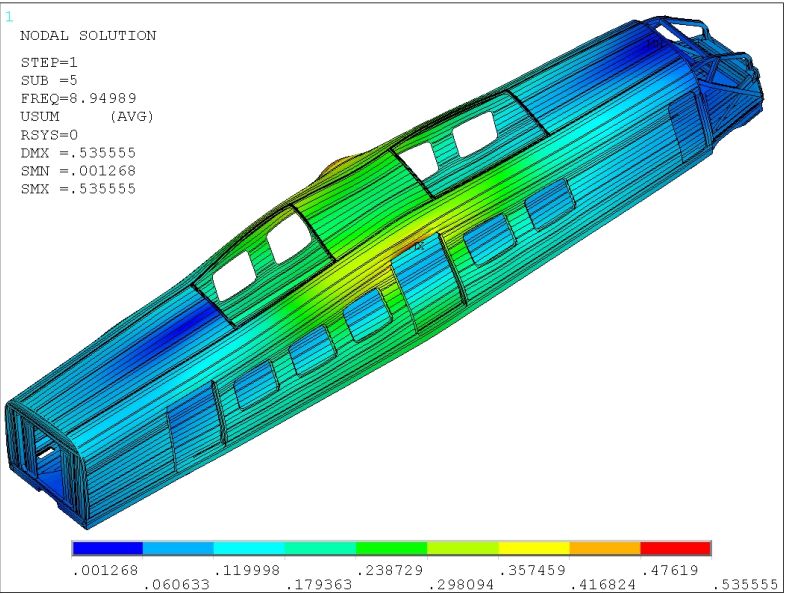

(b) $8.95 \mathrm{~Hz}$

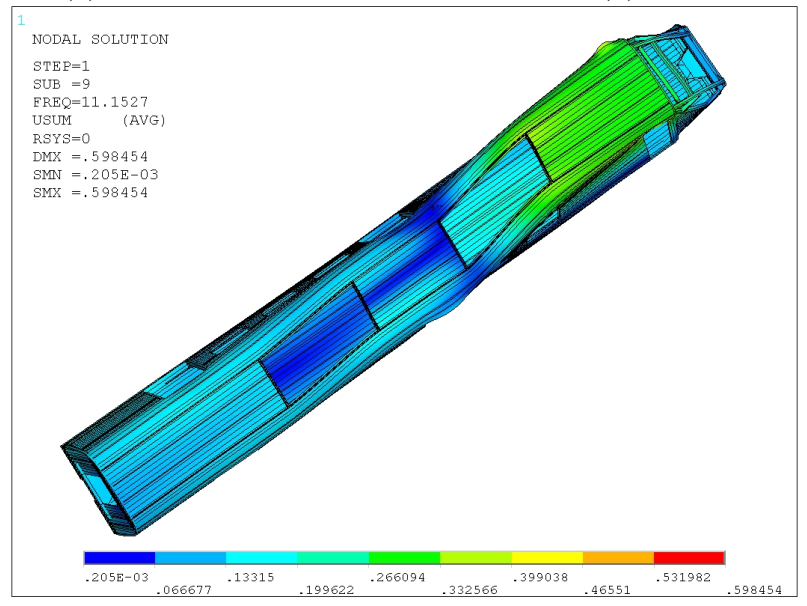

(c) $11.15 \mathrm{~Hz}$

Fig. 3 Some vibration mode and frequency of carbody: (a) vertical bending; (b) rhombic; (c) torsional.

The rigidness-flexiblility coupled vehicle system dynamic model was built as shown in Figure 3. Only the vehicle body was considered to be flexible. And the model contains one flexible carbody, two rigid frames, four wheelsets, eight tumbler axle-boxes, and one underneath equipment. Only one underneath equipment was considered for study convenience,. However, the body, wheelset, and frame and underneath equipment all have 6 degrees of freedom (DOF), and the tumbler axle-box only has one degree of nod. The non-linear characteristics of wheel-rail contact and suspension parameters were taken into consideration. The kinetic equations of vehicle system can be described as follows:

$\mathbf{M} \mathbf{C} x=\mathbf{P}(t)+\mathbf{T} e$

where $\mathbf{M}, \mathbf{C}$ and $\mathbf{K}$ form the mass damping and stiffness matrix of vehicle system, while $\mathbf{x}$ is the coordinate vector. Additionally, $\mathbf{P}(t)$ represents nonlinear elements, such as nonlinear suspension force and wheel-rail contact force. What's more, $\mathrm{t}$ stands for time, and $\mathrm{T}$ symbolizes the distribution matrix of track input and e means track irregularity.

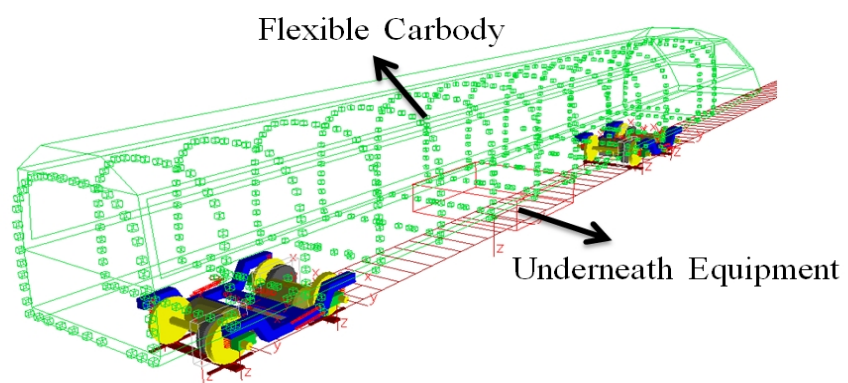

Fig. 4 The 3D dynamic model of rigidness-flexibility coupled vehicle system 


\section{Simulation analysis}

Based on the rigid-flexible dynamic simulation model, the vibration of carbody and underneath equipment was analyzed. Among all the underneath equipments, the traction transformation is chosen because of its weight. The vibration acceleration of two points was measured: one is the centroid of the traction transform and the other is the connection point on carbody. The measured track excitation of Wuhan-Guangzhou line is used to simulate the influence of suspension stiffness and damping ration of rubber element.

\section{Differences between rigid and flexible connection}

The rigid connection was designed to apply to both the underneath equipment of inter-city EMU and the carbody studied in the present research. But the flexible vibration of carbody is so serious that it may cause poor ride index of passengers. Therefore, the paper aims to explore whether the flexible connection between carbody and underneath equipment can decrease the flexible vibration of carbody and improve the ride index.

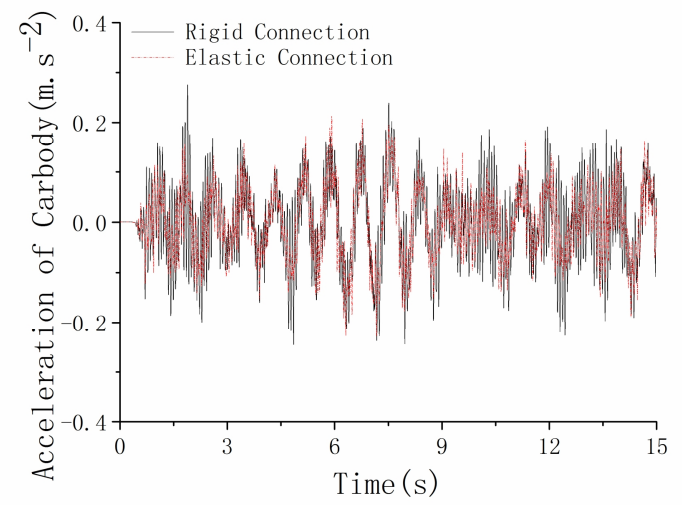

(a) Lateral Vibration

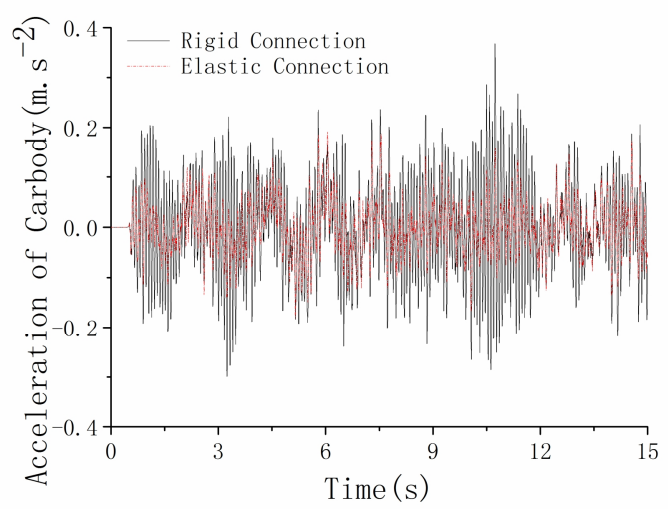

(b) Vertical Vibration

Fig. 5 The influence of different connection ways on carbody vibration under $250 \mathrm{~km} / \mathrm{h}$.

Compared with the flexible connection mode, the rigid connection has a significant influence upon the vibration acceleration of the vehicle body and the vehicle. As shown in Figure 5 (a) and (b), the body of the vehicle body is connected with a flexible connection to a small rigid connection. While the maximum vertical acceleration of the rigid body is connected with the maximum vertical acceleration of $0.368 \mathrm{~m} / \mathrm{s}^{2}$, the vehicle body is linked with flexible connection of vibration $0.193 \mathrm{~m} / \mathrm{s}^{2}$. The maximum lateral acceleration of rigid and flexible connections are $0.276 \mathrm{~m} / \mathrm{s}^{2}$ and 0.229 $\mathrm{m} / \mathrm{s}^{2}$.respectively. It is shown that the device with a flexible connection can help to weaken the influence of the flexible vibration of the carbody, thus improving the dynamic performance of the vehicle. Therefore, it can not only reduce the vibration level of the human body and improve the driving performance of the vehicle, but can also decrease the high frequency vibration of suspension components, and improve its service life.

\section{Influence of suspension stiffness}

Effect of suspension stiffness in body vibration can be achieved by analyzing the root of the body vibration acceleration, which is mainly root mean square value (RMS). In this section, the following vehicle, equipment, and vibration acceleration RMS are to be successively valued to examine the effects of different suspension stiffness, and analysis equipment for the body vibration. Analyses were carried out under the two speed grades: $200 \mathrm{~km} / \mathrm{h}$, and $250 \mathrm{~km} / \mathrm{h}$. 


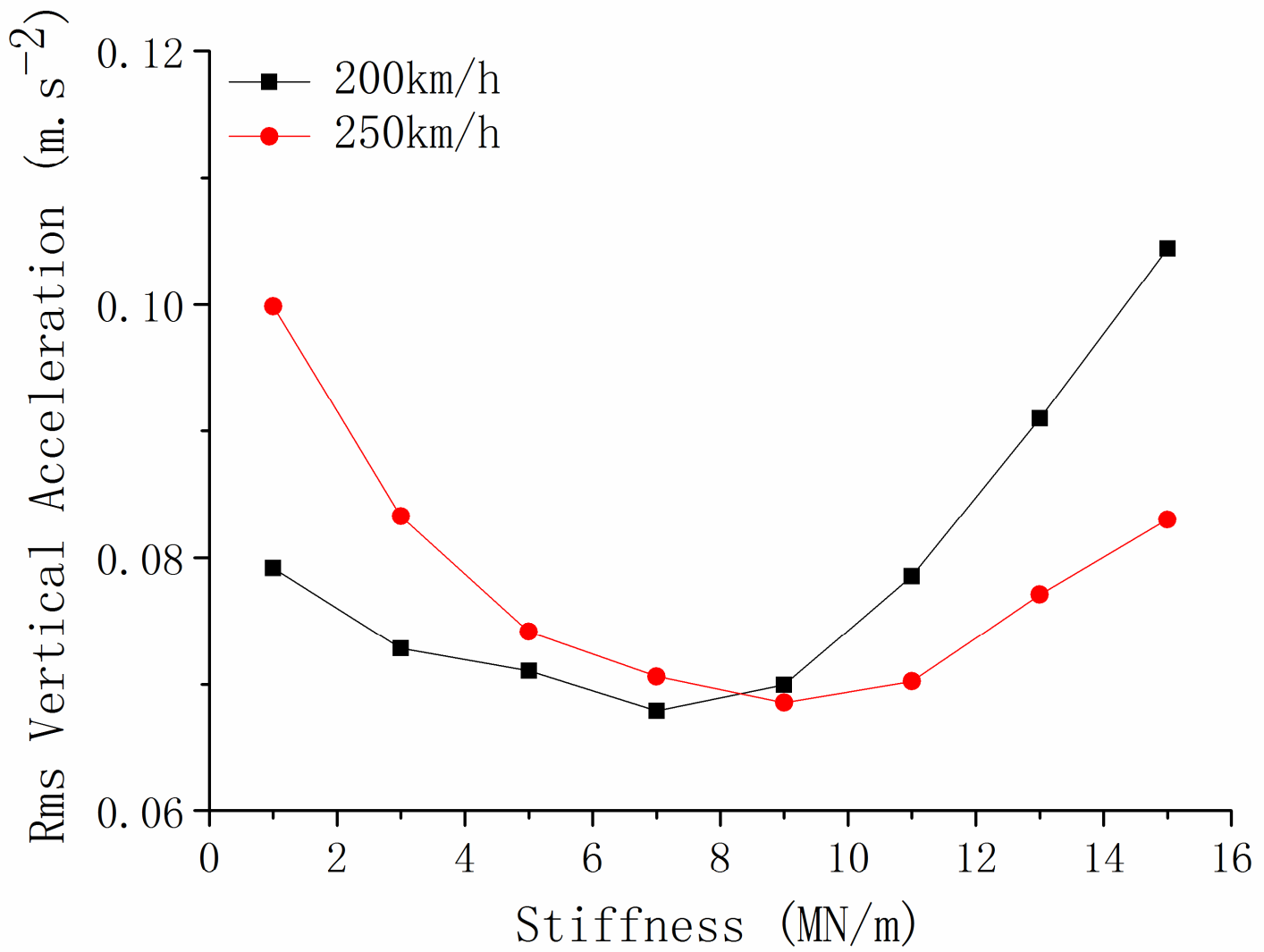

Fig. 6 The influence of suspension stiffness on carbody and underneath equipment.

As shown in Figure 6, when the stiffness of the suspension changes in a certain range, the rubber components can reflect a great vibration damping effect. When the stiffness of the suspension is too low, the displacement of the device is large, and so is the adverse effect of the suspension element, thus resulting in the increase of the vehicle body vibration. More importantly, excessive rigidity may cause failure of rubber damping function. The stiffness of the high suspension can lead to the increase of the flexible vibration of the body, and is not conducive to the device itself at high frequency vibration. In order to satisfy the high-speed operation of vehicles, traction transformer with single stiffness design should be set at $6 \mathrm{MN} / \mathrm{m}$ to $10 \mathrm{MN} / \mathrm{m}$.

\section{Conclusion}

Due to the lightweight design of the vehicle system, the layout of the doors and air conditioning installation holes reduce the stiffness of the car body, which reduces the modal frequency of the car body structure. Moreover, it will deteriorate the flexible vibration of the car body and affect the ride comfort of passengers.

The theory of dynamic vibration absorbers (DVA) is used to reduce the flexible vibration of the vehicle body. Compared with rigid connection and flexible connection, flexible connection can significantly reduce the vibration of the body, especially the vertical vibration.

The effect of flexible suspension parameters expresses itself in reducing vibration. The traction converter is selected as the only underneath equipment because of its weight. Improper suspension parameters will lead to an increase in the vibration of the carbody. In addition, the design of single vertical stiffness of the traction transformer should be set at $6 \mathrm{MN} / \mathrm{m}$ to $10 \mathrm{MN} / \mathrm{m}$.

Other underneath equipments, such as traction converter, brake unit, etc., can also be used to reduce the flexible vibration of the body. Meawhile, appropriate suspension parameters are needed as well. 


\section{Acknowledgments}

This project is financially supported by the National Science Foundation of China (NO.U1334206).

\section{References}

[1] Jing Z., and Ren L., Vibration analysis of railway passenger car systems by considering flexible carbody effect, Journal of the China Railway Society, Vol.29, No.6, pp.19-25 (in Chinese).

[2] Pingbo W., Shihai X., and Chenhui Y., Dynamic response of high-speed passenger car based on flexible car body model, Journal of Traffic and Transportation Engineering, Vol.5, No.2, pp.5-8 (in Chinese).

[3] Joel H., Masayuki T., Tadao T. and Takahiro T., Vibration suppression of railway car body with piezoelectric element (a study by using a scale model), International Journal series C: Mechanical Systems Machine Elements and Journal of Manufacturing Systems, Vol.47, No.2, pp.451-456..

[4] Diana G., Cheli F., and Bruni S., Dynamic interaction between rail vehicles and track for high-speed train, Vehicle System Dynamics, Vol.24, pp.15-30.

[5] Guangbing L., Jing Z. and Qunsheng W., Identifying the relationship between suspension parameters of underframe equipment and carbody modal frequency, Journal of Modern Transportation, Vol.22, No.4, pp.206-213 (in Chinese).

[6] Huailong S., Ren L., Pingbo W., Jing Z. and Jinying G., Application of DVA theory in vibration reduction of carbody with suspended equipment for high-speed EMU, Science China Technological Sciences, Vol.57, No.7, pp.1425-1438.

[7] Young T. and Li C., Vertical vibration analysis of vehicle/imperfect track systems, Vehicle System Dynamics, Vol.40, pp.329-349.

[8] Huichao W., Pingbo W., Jing Z. and Yonglin S., Influence of equipment under car on carbody vibration, Journal of Traffic and Transportation Engineering, Vol.12, No.5, pp.50-56 (in Chinese). 